\title{
MITO, VISIÓN Y TRANSTIERRO \\ EN EL CANGREJO ERMITAÑO \\ DE ARTURO GUTIÉRREZ PLAZA
}

\author{
MYTH, VISION AND TRANSTIERRO IN ARTURO \\ GUTIÉRREZ PLAZA'S EL CANGREJO ERMITAÑO
}

\section{MIGUEL GOMES*}

Resumen: Este artículo examina la poética de Arturo Gutiérrez Plaza tal como se manifiesta en El cangrejo ermitaño (2020), libro que compendia su carrera e ilustra cómo esta ha ido distanciándose del "exteriorismo" predominante en Venezuela hacia 1980. Destacan en su poesía de madurez, por una parte, el diálogo que se establece entre el inventario de lo cotidiano y los mitos; por otra, diversos mecanismos discursivos en los que la referencialidad oscila entre lo directamente anecdótico y una forma que se autonomiza y remite a sí misma. En ambos casos, el efecto resulta similar y sugiere un proyecto creador en el que la experiencia personal se recategoriza en el ámbito de lo transpersonal, sea porque el lenguaje constantemente revela su dimensión colectiva, sea porque lo particular deviene arquetipo numinoso y roza lo metafísico.

Palabras clave: Arturo Gutiérrez Plaza, poesía venezolana, exteriorismo, mito, diáspora.

Aвstract: This article focuses on Arturo Gutiérrez Plaza's poetics as manifested in $E l$ cangrejo ermitaño (2020), a gathering of both previously released texts and abundant new materials showing the author's abandonment of his initial exteriorista style, characteristic of Venezuelan poets in the 1980s. In his mature poetry, on the one hand, a dialogue between daily life and myth has special relevance; on the other hand, diverse rhetorical strategies in dealing with referentiality are also essential, ranging from the most direct and anecdotical to meta-discursive, highly experimental pieces. Both its frequent connection to a mythical sphere and its extreme ways of relating to reality through words produce similar results, since the lyrical voice becomes transpersonal either by diluting its identity into the collective realm of language or by placing itself among numinous archetypes and therefore verging on the metaphysical.

KEYwORDs: Arturo Gutiérrez Plaza, Venezuelan poetry, “exteriorismo”, myth, diaspora.

Recibido: 26.08.2020. Aceptado: 19.03.2021.

* Ph.D. en Literaturas Hispánicas. Board of Trustees Distinguished Professor, The University of Connecticut, Storrs, Estados Unidos. Correo electrónico: miguel.gomes@uconn.edu. Orcid: https:// orcid.org/0000-0002-5296-0420 . 


\section{1. "EXTERIORISMO" Y "VERDADES OCULTAS"}

T a Carrera como poeta de Arturo Gutiérrez Plaza (Caracas, 1962) Uque comprende, entre otros títulos, Al margen de las hojas (1991), Principios de contabilidad (2000), Un sobre sin abrir (2006), Cuidados intensivos (2014) y Cartas de renuncia (2020a) - le ha asegurado un lugar insoslayable en la literatura venezolana reciente. El cangrejo ermitaño (2020b), publicado en España, viene a consolidar ahora su difusión en un ámbito internacional. Entre otros aspectos de su poética, el atinado prólogo de Rafael Courtoisie (2020) destaca la "calidad despojada y esencial de sus recursos retóricos", así como la "cuidada ingeniería" con que se pone a dialogar las distintas piezas en el espacio del libro (p. 9).

Con respecto al primer aserto de Courtoisie, ha de apuntarse que la labor de Gutiérrez Plaza se erige como síntesis de varios estímulos formadores. Ante todo, los debates de la sociedad letrada caraqueña de los años ochenta, con una vocación "exteriorista" -en una acepción próxima a la que se le dio en Nicaragua al término (Cardenal, 1973, p. 7)- y, a la vez, urbana, apegada a los valores modernizadores de la cultura venezolana vigentes aún en las postrimerías del milenio, los cuales incitaban a la ruptura con telurismos para entonces indiscernibles del legado surrealista tal como se había adaptado a la tradición local en la obra de Vicente Gerbasi, especialmente Mi padre el inmigrante (1945) y Los espacios cálidos (1952). Tampoco debe ignorarse el poderoso modelo de Eugenio Montejo - uno de los mayores poetas latinoamericanos de entre milenios-, reacio a los barroquismos, los hermetismos y las manidas contraposiciones de presente y pasado en las poses neovanguardistas -o "neofuturistas", según Marjorie Perloff (1991) quien pensaba en la evolución global de la cultura tras la Guerra Fría (p. 12)-. Y ha de observarse, del mismo modo, la afinidad de Gutiérrez Plaza con la sed de objetividad y precisión, en alianza con la actualización del epigrama, palpable en poetas de más allá de las fronteras venezolanas como Gabriel Zaid o José Emilio Pacheco (Castillo Zapata, 1992, p. 9). El timbre coloquial y el realismo que predominan en sus versos muestran una deuda con el aprendizaje caraqueño de los ochenta, mientras que la capacidad de reconocer las dimensiones metafísicas incluso en los sucesos o los seres más ordinarios - reconocerlas sin hieratismos- indican el enriquecedor ascendiente de Montejo, y sus momentos de destemplada ironía-el "despojo" verbal resaltado por Courtoisie- delatan su frecuentación de cierta poesía mexicana de la segunda mitad del siglo XX. Con tino, Rafael Castillo Zapata (1992) tempranamente captaba lo anterior en una reseña de Al margen de 
las horas, libro que, "sin abandonar el legado conversacional, lo modula[ba] a través de la herencia, rescatada de nuevo, de una poesía menos enumerativa y descriptiva que la exteriorista, y sí más reflexiva" (p. 9). Esa confluencia de materiales en su origen disímiles ha atraído a varios de los lectores subsecuentes de Gutiérrez Plaza. Montejo (2007), en su faceta de crítico, pone de relieve un comercio entre lo "objetivo" y lo "subjetivo", en el que no hay "una mezcla de propósitos requeridos in abstracto, sino la identificación desde su hondura vital del registro que le resulte, por más suyo, más verdadero" (p. 6). Otro tanto ha observado Elizabeth Ortel (2012), y su vocabulario es análogo: "se hilvana lo cotidiano con el registro de experiencias emotivas capaces de revelar verdades ocultas, encarnadas en una escritura que tiene el misterioso poder de enriquecer el espíritu" (p. 19).

Creo que la marca más característica del quehacer de Gutiérrez Plaza se localiza en esas encrucijadas entrevistas por la crítica. Mi propósito es estudiarlas con el detenimiento que hasta ahora no han recibido a la luz de la reorganización de una trayectoria personal que El cangrejo ermitaño postula. En ella se aprecia una superación o un distanciamiento patente del simple "exteriorismo" por la intervención de tres factores cruciales: subtextos míticos; una elocución que no privilegia únicamente la expresión coloquial; y una imaginería que, sin desvirtuar cierta actitud pragmática e incluso materialista, permite lecturas metafísicas.

\section{LAS DIMENSIONES MÍTICAS DE LO COTIDIANO}

La rigurosa construcción de El cangrejo ermitaño que el prólogo de Courtoisie celebra no es inusitada. Cartas de renuncia -publicada casi simultáneamente en Venezuela- divide sus cuarenta páginas en ocho apartados con títulos seminarrativos e irónicos. Pasado en limpio (2006), incluía un tercer poemario inédito -el mencionado Un sobre sin abrir- tras dos secciones que antologan los previos -y ya Principios de contabilidad recogía textos de Al margen de las hojas-. Cuidados intensivos diseñó un repertorio de asuntos mediante siete grupos donde se insertan, entre los nuevos poemas, algunos de la serie "Arqueólogo del aire (diario de un caraqueño en el DF)", procedente de un volumen colectivo (Guía de forasteros, 2012). Como vemos, desde el comienzo, hay ciclos de avance, corrección y redistribución que se aúnan al impulso de inventariar los límites personales del decir, como si un fundamento de la poética de Gutiérrez Plaza fuese el análisis del periplo de su escritura, con la inevitable fabulación de su destino literario 
-solapado retrato de una vida en las letras o, como lo formularía Lawrence Lipking (1981), de la manera como el poeta "convert[s] his experience into vision" ['convierte su experiencia en visión'] (p. X)-. A mayor escala, empresas de ese tipo han producido clásicos como Les Fleurs du mal, Leaves of Grass, La realidad y el deseo y Libertad bajo palabra; archivos, compendios o memorias de lo escrito que valdría considerar un subgénero de la lírica.

Alterando activamente las secuencias de libros precedentes, desechando poemas, retocando versos o añadiendo inéditos de una efectividad expresiva notable, El cangrejo ermitaño hereda el autoexamen, pero lo somete a categorizaciones temáticas más minuciosas que realzan puntos de inflexión hasta ahora discretos, casi escondidos, en el autor. En ocho partes se divide el conjunto, y cada una de ellas traza una provincia creadora: (I) la inquietud política; (II) los desplazamientos geográficos; (III) la violencia y otras facetas ominosas de lo urbano; (IV) el desarraigo; (V) el Eros; (VI) tanteos en las fronteras de la razón; (VII) el destino familiar y el personal; (VIII) la meditación acerca de la poesía.

Ese "tratado" meticuloso sobre el curso de la imaginación y la escritura propias, con todo, por ser a primera vista temático, disimula corrientes subterráneas o zonas más arcanas, inconscientes, de la sensibilidad. Esos estratos recónditos conceden coherencia a los ocho compartimentos. De una u otra manera la crítica en torno a la obra de Gutiérrez Plaza había intuido esto sin tener ocasión de ir a fondo en sus implicaciones. Recuérdense las "verdades ocultas" aducidas por Ortel. Luis Enrique Belmonte (2011) también recalca, entre los datos cotidianos, "zonas ocultas que nos remiten a algo que está ausente o algo que sobra o que se queda ahí, en los resquicios del tiempo" (p. 147). Tampoco ignora los contenidos metafísicos Luis Miguel Isava (2006) cuando sugiere que la laboriosa "mirada" del sujeto poético de Gutiérrez Plaza se constituye "en una siempre incierta y renovada 'anunciación”" (p. 6). Incluso Manuel Iris (2010), quien tanta importancia concede a lo que esta escritura tiene de empírico e inmediato, no puede abstenerse de echar mano de una terminología en la que se presiente un ámbito inmaterial: "La mayor parte de los poemas de Gutiérrez Plaza son objetivos porque suponen la existencia de una poesía exterior que necesita ser revelada" (s.p.); y como "poética de la revelación", ni más ni menos, la describe, concluyendo que todo el peso que su ensayo concede al exteriorismo forzosamente habría de relativizarse: "Debo decir, sin embargo, que en varios momentos de la poesía de Gutiérrez Plaza mi propuesta es rebasada, pues el poeta varía su retórica guiado por intenciones distintas" (s.p.).

El arraigo de la cotidianidad en el mito es uno de los elementos que 
acaban desmantelando todo intento de aprisionar esta obra en el corsé de lo estrictamente empírico. Y las unidades míticas se mueven con libertad, sin esquemas previsibles, a lo largo de El cangrejo ermitaño; congregan y articulan subrepticiamente lo que las ocho partes se empeñan en deslindar. El inframundo -o el viaje a él-, por ejemplo, reaparece, sea en sus variantes cristianas o no. La parte III viene encabezada por un epígrafe de Calvino en el cual se nos advierte de dichas omnipresencias o ramificaciones semánticas de lo que parece latente en la psique profunda: "El infierno de los vivos no es algo por venir: hay uno, el que ya existe aquí, el infierno que habitamos todos los días, que formamos estando juntos" (2020b, p. 43). El Averno pronto se asocia a una alegoría política si tenemos en cuenta que toda la parte III indaga cómo lo hostil o inquietante brota en escenarios claramente sociales; así, en el tercer poema de la sección, hallamos indiscutibles remisiones a la miseria y la abyección que se han adueñado de Venezuela, subrayada con sarcasmo por el contraste entre desarrollo y subdesarrollo en el título - "En una estación del metro no vista por Pound (en Caracas no en París)"-, antes de describir los grotescos malabarismos de "El hombre de escaso muñón" que "descendió a los infiernos" para mendigar con manos extendidas que "imploraban a un bosque de húmedos rostros, / pétalos purulentos sobre negras ramas” (p. 48). El horror se hace más pungente por la elegancia con que se reconstruye la imagen original gracias a una dislocación al principio del verso final de la aliteración de Pound, citada en el epígrafe: Petals on a wet, black bough. Esa moderna catábasis la anticipaba otro poema, "La mujer imaginada" (p. 47), donde también se evoca el metro, esta vez el de México - os viajes son la materia de la parte II, recuérdese- y protagonizado por una figura que, si bien acepta que la interpretemos como personificación del alma o el inconsciente - al estilo surrealista de Magritte y su "Je ne vois pas la / [femme]/ cachée dans la forêt" ['No veo a la / (mujer) / oculta en el bosque']-, no deja de suscitar el presentimiento de insatisfacciones amorosas -dominantes en la parte $\mathrm{V}-$, que tienen igual base mítica: una Eurídice extraviada bajo tierra.

A afirmaciones similares se prestan los poemas que trabajan con el mito del paraíso. "Vengo de un lugar", introducción a la parte II, donde el tema de los viajes se desarrolla, alude desde el título a la visita que le hace Beatriz a Virgilio relatada por este en el segundo canto del Inferno, lo que, de una vez, enlaza directa o indirectamente con las partes IV (desarraigo), V (Eros) y VIII (metapoesía). Lo paradisíaco, por supuesto, también actúa como puente entre los motivos del viaje (II), lo nacional (I) y lo familiar (VII) en un poema como "Tierra de Gracia", cuyo epígrafe colombino nos invita a 
reflexionar en torno a la actual diáspora venezolana desde la perspectiva de la dispersión de los seres queridos, la forzada inmersión en nuevos idiomas $y$, con ello, la injerencia en la realidad de un mito adicional, explícito en la penúltima estrofa: "Destinados a la errancia / somos también los hijos de Babel” (p. 40). La torre veterotestamentaria vuelve a intervenir en la parte IV, en la "Canción para Phillip, mi estudiante de español" (pp. 61-62).

Esas redes que vinculan lo que la epidermis del libro separa contribuyen a delinear la unidad de las vivencias humanas: la voz poética se convierte en una especie de Hermes que nos guía por senderos arquetípicos donde lo expuesto a la luz del día se comunica con lo abismal, o donde lo consabido desemboza su sentido más secreto. La sintaxis velada del poemario es una de las razones por las cuales este esquiva la mera exhibición de lo autobiográfico y colectiviza lo aparentemente privado, corroborando la opinión de Jonathan Culler (2015): "The subjectivity at work in the lyric is a formal principle of unity more than the consciousness of a given individual" ['la subjetividad operante en la lírica es más un principio unificador que la conciencia de un individuo'] (Loc 7048). En El cangrejo ermitaño hay una subjetividad mítica que ejerce un insustituible papel estructurador.

\section{DE LO ANECDÓTICO A LO VISIONARIO}

Las continuidades no son exclusivas del plano referencial: cabe señalar asimismo concordancias expresivas entre poemas de diferentes partes del libro. Tres parecen ser las principales vertientes que se manifiestan. Me atrevería a denominarlas anecdótica, semiótica y visionaria, atendiendo a la ya citada tesis de Lawrence Lipking (1981) de que las "carreras poéticas" esbozadas en ciertos libros intentan trasmutar la "experiencia" en "visión" y eso se logra sugiriendo la narración "iniciática" de un sujeto que busca su destino. Pero el poeta, nos advierte Lipking, "makes it, precisely, with poems [...] It does not exist outside the work of the poet" ["lo hace precisamente con poemas (...) La trasmutación no existe fuera de la obra del autor'] (p. IX); lo que equivale a sustentar que todo ocurre por mediación del lenguaje y en el interior de este: lo edificado por un poeta les pertenece, primordialmente, a las palabras de las que se vale. Veo en los poemas de diversas épocas de Gutiérrez Plaza compilados en El cangrejo ermitaño la alternancia entre la exaltación experiencial y la revelación de lo ilusoria que esta exaltación puede ser cuando se somete en el verso a las leyes del lenguaje. Tal contraste se resuelve en otros poemas que amalgaman ambos 
extremos, propiciando una vez más que contemplemos en la trama de los textos cómo lo personal cede paso a lo transpersonal.

En la vertiente anecdótica -herencia de los paradigmas de la poesía venezolana joven de los años ochenta- una actitud objetiva ante eventos y personajes se despliega sin que la forma llame demasiado la atención hacia sí misma, aunque en el disimulo de esta el poeta dé muestras de pericia. Ello ocurre, por ejemplo, en "Mrs. Gardner" con una versificación tan cristalina que sería indistinguible de la prosa -buena prosa- de no ser por el soporte gráfico. La ausencia de metro cumple la misión de "anunciar al lector que la emoción poética, no la información o el razonamiento, es lo que está esperándolo" -como alegó Borges (1974, p. 976) de su propio cultivo del verso libre-:

Nació tres años después y murió dos antes que su marido. Se trata de la señora Gardner, cuyo nombre de soltera fue Bertie Miller.

No conoció el cese de la Primera Guerra, pero supo que su hijo moriría en la Segunda.

Sospecho que fue feliz, en algún instante de su vida, sin embargo, no hay fotos que lo testimonien.

En esta tarde gris, fría y con neblina es todo lo que alcanzo a ver cuando leo su nombre sobre su tumba (...). (Gutiérrez Plaza, 2020b, p. 57)

Otro poema de linaje idéntico es "El amigo chino":

Desprevenido, acorralado por el colesterol, ese hombre daba vueltas y vueltas en la cuadra donde vivía rodeado de árboles, desde los cuales los pájaros lo veían pasar.

A diario, en su perenne travesía, se encontraba con su amigo chino.

Se saludaban, como siempre, fraternalmente. Ambos sonreían, 
gesticulaban con la mano izquierda

y seguían sus pasos.

A lo largo de sus vidas

nunca cruzaron palabras.

Extranjeros, ejercían su oficio silenciosamente (...). (p. 70)

El quehacer de Gutiérrez Plaza, por otra parte, puede depararnos una modalidad contraria. La llamo semiótica porque los signos se reifican, dejan de ser transparentes para atenuar de modo ostensible la gravitación en ellos de lo "simbólico". Acudo, obviamente, a las distinciones kristevianas (1974, pp. 22-30), pero enfatizando, con críticos y teóricos posteriores, la interdependencia de ambos aspectos del lenguaje (Sadehi, 2012, p. 1491) y su coexistencia: "lo semiótico siempre se manifiesta dentro de lo simbólico" (the semiotic always manifests itself within the symbolic) (Sabo, 2010, p. 59). Lo evidencia el caso de Gutiérrez Plaza, cuyos experimentos en el laboratorio de las formas jamás recaen en la innovación gratuita o las estridencias. Me refiero a una verbalidad como la exhibida por "Cuando llegues", poema en el cual el aprovechamiento de la página se corresponde tan pulcramente con los fenómenos naturales aludidos que estos se convierten en imágenes puras, reemplazados sin añoranza en nuestra conciencia:
$\mathrm{Al}$
llegar
a la playa
del tiempo
descubrirás
en el centro
de la página
un manantial
del que brotan
y resucitan los días
en incierta sucesión.
A
esa
hora
recordarás
y anotarás
todo lo olvidado
para borrarlo de nuevo. 
La

espuma

de las olas

será tu confidente,

reposando sobre la arena

la alisará hasta ocultar tus huellas.

Solo

entonces

te adentrarás en el mar. (pp. 146-147)

Los versos finales indican que el espacio imprescindible es el de nuestra psique, lo cual permite que el horizonte metafísico anterior se reinterprete como una exploración de la palabra; la navegación o la inmersión se producen en el "mar" del lenguaje y en sus olas, que habíamos ido recibiendo una tras otra en cada estrofa. Todo sujeto, toda identidad -de allí la elección de hablarle a una segunda persona, con el efecto de invisibilizar a la primeraes una playa; una orilla se tiende ante la inmensidad de esos flujos y reflujos del sentido y los signos que intentan albergarlo.

"Cuerpos (con)versos" constituye otro ejemplo de este método que cuestiona la primacía de lo no textual. A diferencia de "Cuando llegues", aquí se minimiza el factor caligramático y se explota el arsenal de la métrica, más lo que un diálogo con el canon lírico facilita a un hablante interesado en destacar la materialidad de la escritura. Ello no solo porque la remisión al Siglo de Oro nos sitúe en el terreno de un género específico, el del poema que escenifica su propia construcción, sino por la puesta en abismo que esa intertextualidad supone. Nos las habemos con una composición que hace lo anterior mientras nos recuerda que otras, demasiado clásicas como para no pensar en ellas - "Pedís, reina, un soneto, y os lo hago" de Diego Hurtado de Mendoza, "Yo acuerdo revelaros un secreto" de Baltasar del Alcázar o "Un soneto me manda hacer Violante" de Lope de Vega-, la han precedido:

Este primer verso podría ser mi dedo así, sospechando tu boca. Una palma abierta sobre esta estrofa desnuda, temblando bajo tu piel.

La segunda, dos manos, tu pezón inventado en la mía. Sostenido en la otra, en la tuya, lo prohibido: la antorcha que da lumbre al borrador 
Del otro pecho la izquierda. Dos teas,

dos brasas ardientes, apretujadas

sobre la blanca carne acostumbrada

al fuego impenitente del poema.

El cuarto punto, sí, el ardor hondo,

el vértice de humedad florecida,

el puerto de llegada, cuarta esquina,

el verso final, oscuro y gozoso. (p. 78)

En esta ocasión, los desvíos con respecto al género renacentista -en deuda con el ideal de maestría formal, así como con la "agudeza" y el "ingenio" que Gracián teorizaría a la larga- tienen la misión de hacer hincapié en el protagonismo del lenguaje -quizá más en la tónica y el horizonte filosófico del Objectivism o la Language Poetry norteamericanas; los años vividos por Gutiérrez Plaza en los Estados Unidos explican este giro-. El abandono del soneto y el uso de cuartetas asonantadas, para no ir muy lejos, consolidan la propuesta del título donde los dominios del erotismo y los de la poética se intercambian, y donde el signo, a la vez, muestra su vocación indeterminada, su capacidad de no comprometerse con un referente acatando el imperativo constructivo tanto de quien escribe como de quien lee, que ha de elegir entre los significados bifurcados por el paréntesis. A partir de allí todo es doblez o dualidad: los amantes de la anécdota, pero más la forma que los va absorbiendo y desdibujando, cuatro cuartetas donde todo, casi literalmente, es múltiplo de dos y se acopla gracias a la rima que asocia el primer verso con el cuarto y el segundo con el tercero, por no mencionar las fusiones espontáneas de los frecuentes encabalgamientos hasta casi el final de la composición, el principal tipo de "emparejamiento sintagmático" (syntagmatic coupling) -así lo denominaría Samuel Levin (1977, pp. 30-41) - que se verifica, fundiendo versos a través de la dependencia de sentido. La sensualidad lingüística disuelve la de los cuerpos, se impone a cualquier otra que pudiese haberla precipitado.

La tercera vertiente expresiva de Gutiérrez Plaza, la de lo visionario, favorece un balance entre el habla y el canto, o sea, entre lo anecdótico y lo semiótico, pues nos reincorpora en la vida solo después de enfrentarnos a la acción demiúrgica del lenguaje. Tengo en cuenta, en mi vocabulario, no solo a Lipking -quien jamás se detiene a definir qué entiende por visión-, sino a Carlos Bousoño (1970). En sus palabras, el poeta

usando el procedimiento que aquí llamamos visión, enuncia como propio de $A$ un término irreal $b 1$, que en la realidad pertenece caracterís- 
ticamente a $B$ y que va en $B$ asociado siempre a otros elementos $b 2, b 3$, $b 4 \ldots$ Ocurre además que esa serie $b 2, b 3, b 4$ produce en nosotros un sentimiento $Z$, que, en cambio, $b 1$ no produce nunca por sí mismo en nuestro ánimo. (vol. 2, p. 218)

La visión cristaliza, así pues, cuando en la escritura prevalecen las asociaciones prerracionales o irracionales y se posterga al máximo una denotación que, al cabo, nos alcanza.

Un ejemplo se observa en "Despedida", cuyos versos desnudos, parcos, se eximen de puntuación, entregados, de cierto modo, a la caída de algo que no reconocemos y, no menos, a la condición enigmática de lo que solo se nombra al final obligándonos a despedirnos conjuntamente de la incertidumbre y el poema. Como resultado, en la captación de la materialidad del verso apreciamos el esplendor material del cosmos:

Cae pero flota

danza

se detiene para voltear

para mirar atrás

duda

dice adiós

es torpe al despedirse

ligera baila en el viento

nos tributa

su frágil existencia

su arrepentida levedad

de a poco

nos llena de canas

su piel hace más fría

nuestra piel

humedece nuestros zapatos

nos deja en gratitud

una huella

se despide

nos dice adiós

cae pero flota

ella también

es la nieve. (Gutiérrez Plaza, 2020b, p. 72)

Otro caso memorable lo hallamos en la pieza titulada, con sencillez engañosa, "Poema", donde nuevamente se divisa una confluencia armónica de la inquietud vital y la inquietud por la relación del mundo con los signos: 
¿Cómo podría escribirlo?

Tal vez, habría que dejarlo solo.

Sin molestarlo y sin testigos

sin obligarlo a contestar.

Que su franqueza no estuviera en las palabras.

Que los cuerpos en secreta cofradía

ocuparan el centro de la página.

Que lo habitara una escondida sonoridad, una indócil atadura al deseo.

¿Cómo podría escribirlo?

¿Cómo podría la desnudez sin ti? (p. 79)

La conducta semiótica hace que el tema del deseo y las dificultades de acceder al Otro se desplieguen en las tensiones visuales entre el dos y el uno, entre versos aislados y pareados. Las dos preguntas del desenlace, pese a ello, parecen compensar el desarrollo anterior actualizando la precedencia de lo vivido o lo sentido por sobre cualquier articulación que pretenda dársele: a fin de cuentas, los interrogantes nos colocan ante las incertidumbres de lo indecible o, incluso, una inefabilidad erótica. Y un equilibrio similar se obtiene por vías más indirectas, puesto que la sintaxis que establece El cangrejo ermitaño entre las piezas que congrega nos invita a releer especularmente "Cuerpos (con)versos" (p. 78) y este "Poema", dispuesto a continuación. Si el primero de ellos jugaba a diluir el gozo carnal en el puro gozo rítmico, en el segundo la autonomía del significante parece pactar con la urgencia del significado cuando apreciamos que justo hacia la mitad del texto tenemos un par de versos que, sin perder su metadiscursividad, se las arreglan para recordarnos sus deudas con lo real: "Que los cuerpos en secreta cofradía / ocuparan el centro de la página”. Como si una integración de vida y literatura fuese la máxima aspiración: la comunión de los amantes es la del poeta con su arte.

\section{TRANSTIERRO Y ASCESIS}

Y ya que se ha hecho necesario hablar del asunto, tal vez dos sean las facetas decisivas de la "vida" en el tipo de recuento que este volumen instaura: 
transtierro y ascesis. Decisivas las considero por surgir en el paratexto que instaura la matriz hermenéutica fundamental: no olvidemos que estamos ante una summa que plasma una "carrera poética", en la acepción que da Lipking al término. El cangrejo ermitaño es un título que, como lo expresaría Gérard Genette (1987), incita cierto tipo de lecturas unificadoras gracias a su facultad "connotativa" (pp. 85-87). El triunfo de un vitalismo irracional y visionario se prepara desde la imaginería con que el autor elige encabezar su libro.

No obstante el verbo transterrar quede torpemente definido en el Diccionario de la lengua española (2019) de la RAE como "Expulsar a alguien de un territorio, generalmente por motivos políticos", lo que convertiría el transtierro en un mero sinónimo de exilio -recuérdese: la pena de muerte eufemizada en los argumentos de Cicerón: Exsilium enim non supplicium est sed perfugium portusque supplicii ['el exilio no es suplicio, sino refugio y santuario del suplicio'] (ver Cicero, Pro Caecina 34.100)-, aquí adopto el vocablo en una acepción cercana a la que le confirió José Gaos (1994) al acuñarlo: transfiriendo el énfasis en la pérdida de un territorio a la comprensión de que ese territorio es, hasta cierto punto, móvil, puesto que sus fronteras no son exclusivamente físicas, sino mentales o culturales. "Confesiones del transterrado" es solo uno de los muchos escritos donde Gaos, asentado en América, reflexionó sobre las limitaciones políticas de la noción de exilio y, aunque su iniciativa algo tenía de urgente optimismo en medio del sombrío cuadro de la Posguerra española, me parece adecuado rescatar el término en la coyuntura venezolana en la que Gutiérrez Plaza ha seguido replanteando su obra. Su primer poemario, téngase en cuenta, es de 1991: apareció cuando el sueño de un país próspero y democrático había dado, en la década previa, señales de disiparse, de haber sido un espejismo desarrollista o un paréntesis excepcional en una prolongada historia de autoritarismo, violencia e inestabilidad. Quienes crecieron y se formaron en la Venezuela de los sesenta y setenta sintieron en la transición del milenio que, en gran medida, su país ya no existía o, peor, jamás había existido del todo. Buena parte de la literatura venezolana de los albores del siglo XXI ha inventariado ese malestar. Alexis Romero (2020) sostiene que en Cartas de renuncia se aborda "la tragedia política, social y cultural" que vive una nación, exponiendo "nuestros conciertos y desconciertos; nuestras costumbres arcádicas y premodernas; nuestras adicciones por lo mesiánico, nuestro desprecio por las obras de lo civilizado, nuestra fiesta por lo militar y bárbaro", haciendo del poeta el testigo de "un país que violentamente fue destruido" (p. 43). La destrucción también invadía numerosos trechos de 
Cuidados intensivos (Gomes, 2014, pp. 140-141). Pero la opción cifrada en El cangrejo ermitaño, si bien sus páginas a veces denuncien la degradación y las ruinas de un entorno indisputablemente nacional, acaba siendo sutil y matizada. Ante el colapso de un mundo fraudulento, el poeta apuesta por una reformulación de sus tratos con la realidad y, en particular, renegocia cómo ha de instalarse en ella el sujeto. El transtierro de Gaos amplía ahora su tenor metafísico: quien pierde el que creía su centro tiene la opción de encontrarlo en sí mismo. Somos nuestro lugar de pertenencia y el instante en que lo percibimos es nuestro tiempo de plenitud existencial. Jamás dejamos de dialogar con las circunstancias inmediatas, espaciales o cronológicas, lo que significa aceptar que nuestra identidad va rehaciéndose en un viaje en el que el aquí difiere del allá tanto como el presente difiere del pasado: como si nuestro origen cada día se ensanchara más y hubiésemos estado domiciliados en nuestro destino desde momentos imprecisables. Un domicilio portátil, invisible.

Esa intuición es la que palpita en un poema como "Trastiempo" que, amén de un homenaje al Eugenio Montejo de Alfabeto del mundo (1987), Papiros amorosos (2002) y Fábula del escriba (2006) (Montejo, 2020, pp. 220, 404, 450, 457-467), es un ars poética donde el diálogo con el Otro nos dispensa la clave de nuestra intimidad:

Ayer caminaré por la noche que terminó sobre esta línea.

Me detendré cuando sentí que no fue un abismo sino un puente colgante sobre puntos suspensivos. Hacia atrás avanzaré persiguiendo una sombra, tal vez la que seré, la que fue mía.

$\mathrm{Al}$ iniciarse la oscuridad arribaré al momento que entreveré antes.

En lo alto del crepúsculo bajaré hasta la cima de este poema que comenzaré sobre esta línea, poco antes de partir. (Gutiérrez Plaza, 2020b, p. 137)

El ser es tránsito para alguien comprometido con el lenguaje como forma de conocimiento; alguien que sabe que el significado definitivo es una imposibilidad, dado que el signo obedece a combinatorias, sea en contextos 
presenciales -las palabras afectadas por otras en el enunciado- o potenciales -las palabras vinculadas u opuestas a otras que no se han materializado en un enunciado-. Si el logos no ofrece un centro, un punto para el arraigo absoluto, hemos de aceptar que la metáfora crucial de El cangrejo ermitaño es la del flujo o el nomadismo como únicos hogares auténticos. Y "Hogar" se titula un poema que suma todas las operaciones de traducción de lo crudamente físico en una ontología:

Vivo en esta ciudad, en este país despoblado, avergonzado por sus propios fantasmas, confinado a cuatro paredes hurañas.

Vivo en cuartos vacíos.

En habitaciones que a ratos se encogen

expulsando todo aquello

que hasta ayer me acompañaba.

[...]

Pero soy de acá, este es mi hogar

y aunque me vaya, aunque me escape lejos,

este encierro siempre será mío.

Vivo como el cangrejo ermitaño, como un decápodo errante, refugiado en conchas vacías, atrapado, impenitente, confiado

en la bondad de alguna ola que me arrastre

o termine de ocultarme en la arena. (p. 29)

Esas marinas que se avistan en los versos de Gutiérrez Plaza -no olvidemos las de José Emilio Pacheco; tampoco sus cangrejos (2007, p. 14)-; la imagen de la playa, la arena, el oleaje, constituyen, como ya lo he sugerido, un oblicuo autorretrato del poeta en su relación activa y creadora con el idioma. Una composición incluida en la parte VIII lo confirma: "Como algas que quedan en la orilla / luego del paso de la marea, / hay palabras abandonadas / que se van secando sobre la página" (Gutiérrez Plaza, 2020b, p. 158). Pero he discutido también suficientemente la importancia de ese registro semiótico y sus síntesis visionarias con la experiencia. Lo que no he resaltado todavía es la escéptica o laica religiosidad de esta poética. Aunque en una primera impresión el adjetivo ermitaño dramatice la soledad, no tardamos como lectores en distinguir los elementos esenciales del tropo insinuado por el título o, mejor dicho, no tardamos en percatarnos de que se 
trata de una metáfora al cuadrado, una analogía que surge de otra u otras, en un laberinto semántico similar al teorizado por Bousoño: la ermita, además de aislamiento, supone una peregrinación interior a lo sagrado, una vez que nos desengañamos de las falsas promesas del exterior $-y$, en lo que a literatura respecta, del exteriorismo-. El "trastiempo" solo puede habitarse, ciertamente, en una región anímica no sometida a la razón.

Con todo, si he anticipado laicidad en la actitud básica del poeta es porque en sus versos la inefabilidad absoluta del éxtasis solamente se vislumbra o anhela. Lo ilustra una pieza como "Si me permites", cuya lectura rasante desencadena interpretaciones eróticas que, tras un análisis detenido, se manifiestan como deseo no agotable en lo carnal:

Si me permites

no te llamaré por tu nombre, procuraré otros atajos que me sepan conducir al sitio donde las palabras amanecen, al recodo donde las historias se reconocen inútiles y el azar pacta a riesgo de sus mejores apuestas.

Si me permites te desearé simplemente como si invocara la lluvia en la estación más seca, aquélla que queda sin balbuceos más allá de la aridez del recuerdo de lo que no fue.

Si me permites, si hay un lugar donde yo pueda, me haré hábito en tu piel y como un devoto feligrés, fiel a los caprichos del deseo te haré mía sin nombres sin palabras, sin promesas. (pp. 87-88)

La cartografía elocutiva nos lleva de lo amoroso a lo poético y de allí, en la tradición mística, a un tipo de espiritualidad, de numinosidad -"el sitio 
donde las palabras amanecen"- no exenta, sin embargo, de ironía, puesto que el andamiaje del texto, con su anáfora donde la amabilidad pragmática y el galanteo se alían, nos hace conscientes de que el lenguaje en situación literaria construye y a la vez deconstruye cada una de sus propuestas: es artificio. La postulación indirecta del decir como tarea aleja la escritura de Gutiérrez Plaza de toda sospecha de iluminación sobrenatural, contribuyendo a afiliarla, más bien, a una ascética en concordancia con la imagen ductora del ermitaño. No escasean las ocasiones en que el acto de hablar o el de escribir se equiparan al ansioso esfuerzo de orar; ello no solo en "Plegaria" -otro poema que acepta lecturas amorosas- (p. 76), sino también en "Urgido en ti" -estremecedor llanto por la muerte de una madre- (p. 131).

Cabe recalcar que una de las virtudes de ese proyecto creador es la obtención de un raro balance -he acudido antes al término- tonal o formal. Los momentos de pathos o abyección, sin que puedan evitarse tratándose de un poeta de la hora venezolana actual, no abundan y se reprocesan con tacto. Por otra parte, así como el asceta emprende la tortuosa vía purgativa en su demanda de santidad, el personaje característico de la poesía de Gutiérrez Plaza parece rehuir los extremos y, a las poses sacrificiales, prefiere casi siempre los ritos de lo cotidiano: ser el habitante de la ciudad; el amigo; el padre; el hijo; el amante perplejo o infeliz, y hasta el hombre divorciado. Si una que otra vez atisba lo sagrado, es igualmente verdad que puede dedicarle guiños satíricos a la trascendencia desbocada, como ocurre en "Mal tiempo", meditación acerca de nuestra efímera existencia en la que una ensoñada inmersión en las aguas del Ganges se produce durante los trámites de la ducha (p. 151); o en "La voz de la Divinidad", en torno a las plegarias orgásmicas de las cuales son capaces algunos vecinos (p. 64). "Qué le vamos a hacer / si uno le reza a Dios / y es ateo", comenzaba un poema de Al margen de las hojas (1991, p. 54), no recogido en El cangrejo ermitaño al pie de la letra, pero sí al pie del espíritu. Estamos ante una poesía que no descarta la existencia de lo divino, aunque tampoco vacila en desendiosarse, porque no otra cosa puede agregarse a la concisión epigramática con que nos conmina a aterrizar "Mis zapatos":

La usual asimetría de sus cordones, los tacones gastados en sus partes menos arrepentidas, su permanente falta de brillo, su escaso sentido del humor y del ritmo son todas huellas que me delatan y hablan de una consumada torpeza para pisar el mundo 
y del descuido con que ambos,

en forzada compañía,

llevamos la existencia. (2020b, p. 120)

Poeta de vuelo cuya identidad sabe volver a ser humana para adentrarse, con serena melancolía, en su condición opaca y mortal: no se me ocurre otra palabra más exacta que lucidez para nombrar el despojo que las mareas -vitales, poéticas- van dejando en las arenas de esta escritura, como un inesperado bien que se le arrebata a una época, por demás, oscura.

\section{REFERENCIAS}

Belmonte, L. E. (2011). Pasado en limpio de Arturo Gutiérrez Plaza. En K. Hernández Consalvi (comp.). Las palabras de El Buscón (pp. 147-148). Caracas: Equinoccio.

Borges, J. L. (1974). Obras completas. Buenos Aires: Emecé.

Bousoño, C. (1970). Teoría de la expresión poética. (2 vols. $5^{a}$ ed., versión definitiva). Madrid: Gredos.

Cardenal, E. (1973). Presentación. Poesía nicaragüense (pp. 7-10). La Habana: Casa de las Américas.

Castillo Zapata, R. (1992). Al margen de las hojas de Arturo Gutiérrez Plaza. Actual, abril, 8-9.

Cicero, M. T. (1927). Pro Lege Manilia. Pro Caecina. Pro Cluentio. Pro Rabirio Perduellionis Reo. Orations, Vol. IX. London: Loeb.

Courtoisie, R. (2020). Arturo Gutiérrez Plaza: palabras que saben dudar, prólogo. En A. Gutiérrez Plaza, El cangrejo ermitaño (pp. 7-14). Madrid: Visor.

Culler, J. (2015). Theory of the Lyric. Cambridge, Mass.: Harvard University Press. Ed. digital.

Gaos, J. (1994). Confesiones del transterrado. Universidad de México, 521, 3-9.

Genette, G. (1987). Seuils. Paris: Éditions du Seuil.

Gerbasi, V. (2000). Mi padre el inmigrante. Xalapa: Gobierno del Estado de Veracruz.

Gerbasi, V. (2005). Los espacios cálidos y otros poemas. Valencia: Pre-Textos.

Gomes, M. (2014). La tarea del lector. Epílogo a Arturo Gutiérrez Plaza. Cuidados intensivos (pp. 133-134). Caracas: Lugar Común.

Gutiérrez Plaza, A. (1991). Al margen de las hojas. Caracas: Monte Ávila.

Gutiérrez Plaza, A. (2000). Principios de contabilidad. México D.F.: Práctica Mortal.

Gutiérrez Plaza, A. (2006). Pasado en limpio. Luis Miguel Isava, presentación. Caracas: bid \& co/Equinoccio.

Gutiérrez Plaza, A. (2012). Arqueólogo del aire (diario de un caraqueño en DF) en Guía de forasteros. Antología (pp. 13-44). México D.F.: Programa de Re- 
sidencias Artísticas para Creadores de Iberoamérica y de Haití en México/ FONCA/Centro Cultural de España en México.

Gutiérrez Plaza, A. (2014). Cuidados intensivos. Miguel Gomes, prólogo. Caracas: Lugar Común.

Gutiérrez Plaza, A. (2020a). Cartas de renuncia. Alexis Romero, epílogo. Caracas: La Poeteca.

Gutiérrez Plaza, A. (2020b). El cangrejo ermitaño. Rafael Courtoisie, prólogo. Madrid: Visor.

Kristeva, J. (1974). La Révolution du langage poétique. Paris: Éditions du Seuil. Iris, M. (2010). Hacer poemas para revelar poesía: acercamiento a la poética de Arturo Gutiérrez Plaza. Agulha Hispânica, 02, http://www.jornaldepoesia. jor.br/BHAH02plaza.htm

Isava, L. M. (2006). Pasado en limpio. Presentación de Arturo Gutiérrez Plaza, Pasado en limpio (pp. 5-7). Caracas: bid \& co/Equinoccio.

Levin, S. (1977). Linguistics Structures in Poetry. New York: Mouton.

Lipking, L. (1981). The Life of the Poet: Beginning and Ending Poetic Careers. Chicago: The University of Chicago Press.

Montejo, E. (2007, junio-julio). Cifras de poemas futuros. Veintiuno, 4.17, 6.

Montejo, E. (2020). Obra completa. Vol. I Poesía. A. López Ortega, M. Gomes y G. Yáñez Vicentini (eds.). Valencia: Pre-Textos.

Ortel, E. (2012, 18-19 de febrero). Pasado en limpio: una voz reflexiva sobre la cotidianidad, Tal Cual, 18-19.

Pacheco, J. E. (2007). Los trabajos del mar. Poemas 1979-1983. México: Era.

Perloff, M. (1991). Radical Artifice: Writing Poetry in the Age of Media. Chicago: The University of Chicago Press.

Real Academia Española (actualización de 2019). “Transterrar”. Diccionario de la lengua española. DLE 23.3. RAE.es.

Romero, A. (2020). La memoria: el hogar de la renuncia, epílogo a Arturo Gutiérrez Plaza, Cartas de renuncia (pp. 42-44). Caracas: La Poeteca.

Sabo, P. (2010). Impossible mourning: Lamentations as a text of melancholia. Tesis de maestría. Edmonton: University of Alberta.

Sadehi, C.T. (2012). Beloved and Julia Kristeva's the semiotic and the symbolic. Theory and Practice in Language Studies 2(7), 1491-1497. 